Article

\title{
Fire Evacuation in Metro Stations: Modeling Research on the Effects of Two Key Parameters
}

\author{
Chen Wang * and Yanchao Song \\ Intelligent Transportation Research Center, Southeast University, Nanjing 210096, China; 220173180@seu.edu.cn \\ * Correspondence: wkobec@hotmail.com
}

Received: 13 December 2019; Accepted: 15 January 2020; Published: 17 January 2020

\begin{abstract}
Metro lines have undergone a rapid development in China and a large number of metro stations have also been built. The passenger traffic volume has reached or exceeded the designed transport capacity in some big cities such as Beijing and Shanghai. The safety evacuation problem within metro stations under emergency has become a worldwide concern. In this study, BuildingEXODUS was employed as the simulation platform and a metro station in Shanghai was selected for model development. Based on field survey data, the evacuation process in different fire cases was simulated, so as to evaluate the effects of two parameters (i.e., escalators and automatic ticket checkers) on evacuation performance. The research found that the use of two stopped escalators (normal metro stations have two) as fixed evacuation passages is effective and essential for safety evacuation. However, it surprisingly decreases the evacuation efficiency if using only one stopped escalator as the fixed evacuating passage. The evacuation efficiency can be improved by opening the automatic ticket checkers compared with maintaining normal status. Removing the automatic ticket checkers does not pose any difference in improving evacuation efficiency.
\end{abstract}

Keywords: fire evacuation; metro station; escalators; automatic ticket checkers; evacuation efficiency

\section{Introduction}

With the rapid development of urbanization, large-scale metro lines have been constructed in many cities of China. By 2020, the total metro mileage will reach over $8500 \mathrm{~km}$ in China [1]. However, metro passenger flow has also been rapidly increasing in many large cities such as Beijing and Shanghai, where passenger demand can even reach $130 \%$ of the original capacity [2]. Since a large number of people could potentially gather around metro stations, trampling and casualties would occur when emergencies happen. Many incidents [3,4] that occurred in metro stations have caused serious casualties and property losses. Thus, safe metro evacuation should be considered an important research topic.

Studies related to metro evacuation mainly focused on identifying the factors affecting evacuation, and developing the simulation modeling methods of evacuation [2]. The factors affecting evacuation include occupant factors (e.g., walking speed, occupant density, exit selecting, etc.), building parameters (e.g., exit width, stair/lift width, etc.), and environmental factors (e.g., fire and smoke etc.). Jiang et al. [5] studied passenger flow characteristics such as maximum walking speed and the width of staircase utilized per person at staircase in metro stations. Lei et al. [6] studied the influence rules of occupant density and exit width on evacuation efficiency. He et al. [7] conducted an investigation on evacuation behaviors of occupants in metro stations. Zia et al. [8,9] examined three factors that could affect metro evacuation efficiency: potential map, evacuees' familiarity of the exits, and exits usage.

Due to safety concerns and the complexity of logistics, the studies of emergency evacuation in metro stations are difficult to be conducted at fields. Thus, the simulation modeling methods are often developed and used by researchers [10,11]. As for metro simulation, many models [12] have been used for evacuation modeling, such as BuildingEXODUS [13], Pathfinder 2011 [14], STEPS [15], etc. 
Some simulation models are proposed or improved by scholars to simulate the evacuation process. They focused on various aspects about evacuation, such as behavioral rules of evacuees including path choice [16], dynamic characteristics of exits during evacuation [17], as well as the efficiency of simulation [18].

As mentioned above, metro emergency evacuation could be affected by a number of factors. In large cities, such as Shanghai, metro stations are normally very large so that building factors could play important effects on evacuation. Thus, in this study, two parameters (i.e., escalators and automatic ticket checkers) were examined in order to evaluate the capacity of metro stations and improve fire evacuation efficiency. The findings are expected to provide valuable information for metro managers for emergency evacuation.

\section{Method}

Simulation modeling methods are often used in the performance-based evacuation design $[10,11]$ due to safety concerns and the complexity of logistics of conducting field research. BuildingEXODUS was employed in this study to evaluate the evacuation performance in a metro station. BuildingEXODUS is a fine network model which can simulate both emergency evacuation and normal circumstance in complex structures. Two-dimensional grid of nodes constructs the simulated environment typically composed by floors, stairways, exits, and occupants determined by an individual set of heuristics of rules [19]. The model provides four operation sub-models to simulate evacuation process: geometry, occupant, scenario, and simulation sub-models. Every sub-model will be used in order to simulate one evacuation situation.

It should be noted that the reliability of evaluation results partly depends on the accuracy of model input, such as geometric parameters and behavioral data. Under this condition, the model input in this study has been carefully calibrated and validated based on actual field data. Thus, it is believed that the findings in this study are reliable and provide valuable information for safety design, as well as emergency management of a metro station.

\section{Model Case Study}

Shanghai Metro is one of the most advanced metro systems in China. By 2014, 548 kilometers of metro lines and 337 stations were constructed and the daily average number of passengers transported by metros is 5 million [20]. The real volume of passenger transport at some metro stations in Shanghai is higher than the rated capacity and the evacuation passage may not satisfy the requirement of emergency evacuation. Thus, it is important to evaluate the evacuation capacity of metro stations and study the effects of key parameters on evacuation performance of metro stations.

\subsection{The Metro Station}

The metro station considered in this study is an interchange station of line 1 and line 10 located in Shanghai, China. It is a typical station with two floors underground. The first floor is the platform layer composed of one island platform and two lanes on either side of it (see Figure 1a). The train of each line is composed of 8 cars and each car has five doors. The second floor is the hall level where passengers leave the station or transfer metro line. There are four groups of automatic ticket checkers on the hall level (see Figure 1b) and the width of each ticket checker is $0.5 \mathrm{~m}$. The first floor and the second are connected by two stairs in the middle of the platform and two escalators as well as two stairs on both sides of the platform. The sizes of the stairs are all $2.5 \mathrm{~m} \times 16 \mathrm{~m}$ and the sizes of the two escalators are all $1 \mathrm{~m} \times 12 \mathrm{~m}$. The probable escape direction is represented in Figure 1 . 


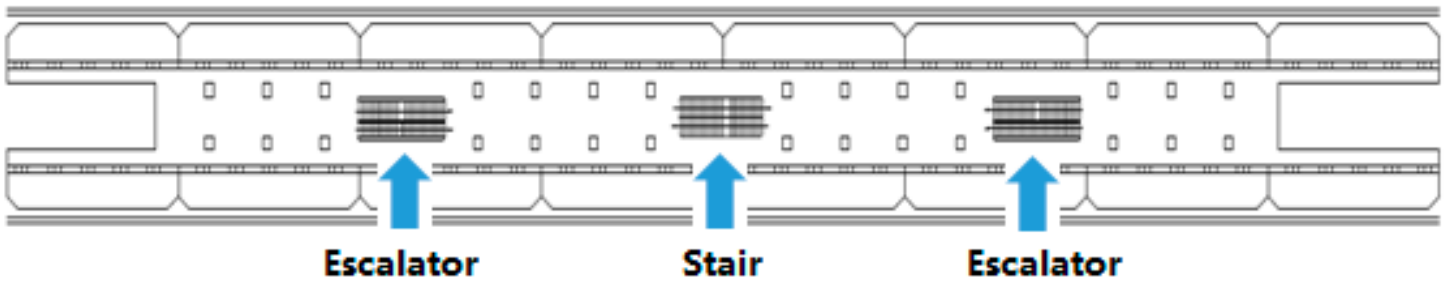

(a) Sketch layout of platform layer.

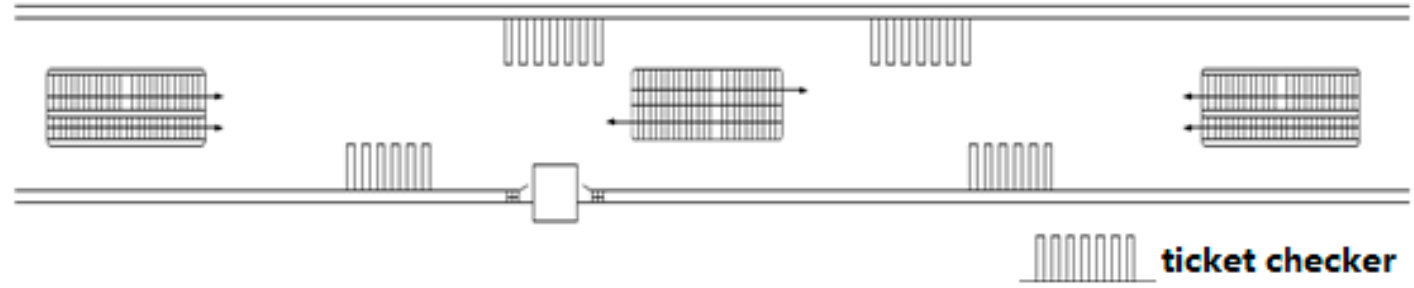

(b) Sketch layout of hall level.

Figure 1. Sketch of the metro station.

\subsection{Model Input Calibration}

Before applying simulation, a set of simulation parameters is required. In this study, field data were collected to calibrate those simulation parameters. The underlying assumption is that those are able to considerably reflect human behaviors under emergency in metro stations.

The total number of evacuated occupants is an important input parameter, which should be carefully calibrated. In order to test the evacuation capacity of the station, the maximum gathered passenger should be taken as the total number of evacuated occupants. The passenger flow of South Shanxi Road station was recorded in October 2014 (31 days) at one-hour intervals and processed as average hourly flow (shown in Figure 2). As Figure 2 shows, the passenger flow in one day is unbalanced and significantly divided into morning peak, flat peak, and evening peak. The maximum gather passenger number is 6718 which appears between 18:00 19:00. According to the passenger flow statistics, the maximum section of passenger flow is 39,456 persons/hour. The train in Shanghai metro line 1 is equipped with 8 vehicles. Eighteen pairs of trains arrive at this station at evening peak hour. Based on the above analysis, the maximum gathered passenger in the station can be figure out as follows:

(a) The maximum passenger capacity of one train at evening peak hour: $39,456 /(18 \times 2)=1096$ persons

(b) The maximum gathered passenger on the platform can be calculated as follows: $6718 /(18 \times 2)=$ 373 persons.

(c) The number of working staffs in South Shanxi Road is 5 persons.

Gender and age are two important simulation parameters, which classify occupants into several groups with different walking speed, responsiveness, and flexibility. The two parameters were determined based on field survey data and literature data: Males: 10-18: 7\%, 19-29: 11\%, 30-50: 33\%, 51-80: 3\%; Females: 10-18: 5\%, 19-29: 13\%, 30-50: 25\%, 51-80: 3\%. According to previous studies, walking speed can be influenced by visibility in the case of fire. When occupants are walking in the condition of heavy handicapped visibility, the fast walking speed of occupants on the floor had a range of $0.22-1.08 \mathrm{~m} / \mathrm{s}$, and the walking speed at the stairs was $0.53 \mathrm{~m} / \mathrm{s}$ [21]. The above walking speeds were employed in this study due to the worst case should be considered when analyzing evacuation capacity in metro stations. Note that, the fastest walking speed on the floor (i.e., $1.08 \mathrm{~m} / \mathrm{s}$ ) employed in this study is lower than the previous research (e.g., $1.20 \mathrm{~m} / \mathrm{s}$ in [22]) probably due to the worse visibility. 


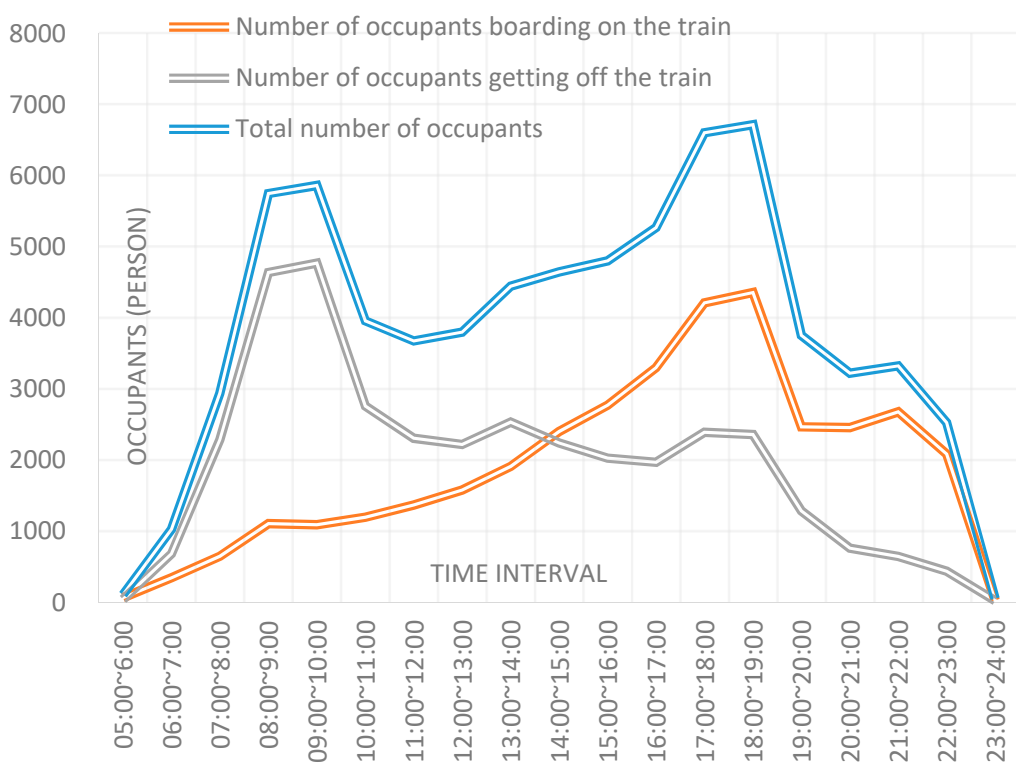

Figure 2. Passenger flow statistics at South Shanxi Road station.

\subsection{Experiment Settings}

In order to analyze the evacuation capability of the platform as well as the effect of key components (i.e., elevator and automatic ticket checkers) on evacuation efficiency, we considered three different fire cases and multiple evacuation strategies (as shown in Figure 3). For fire cases:

Case 1: Fire has occurred on the platform.

When a fire has occurred on the platform, trains should be arranged to pass through the station without a stop. Occupants on the platform must be evacuated to the concourse. In this case, the total number of evacuees is 378 persons.

\section{Case 2: Fire has occurred in a train which arrives at the station.}

When a fire occurs in a train, if a train on the other line is also pulling into the station, the staff should inform the driver to stop or pass through the station. Thus, the occupants in the burning train and on the platform must evacuate to the concourse. In this case, the total number of evacuees should be: $1096+373+5=1474$ (persons).

Case 3: Fire has occurred in a train when two trains are in the station.

When a fire occurs in a train and another train is also arriving at the station, all occupants in the two trains and on the platform must be evacuated to the concourse. In this case, the total number of evacuees should be: $1096 \times 2+373+5=2570$ persons.

About evacuation strategies, stairs and escalators were considered as evacuation passages from trains or platform to the concourse. In order to analyze the effect of elevators and automatic ticket checkers on the evacuation efficiency, six evacuation strategies with a combined use of elevators, stairs, and ticket checkers were simulated. The details are shown in Table 1.

Three basic evacuation strategies (i.e., S1, S2, and S3) were simulate to evaluate the effects of different use of escalators on evacuation efficiency, under three fire cases (see Table 1). For those strategies, to avoid circuit short and electric fire, all escalators were assumed to stop running. For strategy 1 (i.e., S1), no escalator was used as a fixed evacuation passage, and occupants were only allowed to escape through stairs. For strategy 2 (i.e., S2), one escalator and all stairs were used as fixed evacuation passages while the other escalator is out of use. This strategy can be considered as an "unbalanced" evacuation strategy. For strategy 3 (i.e., S3), two escalators and all the stairs were used as fixed evacuation passages. Both S1 and S3 can be geographically considered as "balanced evacuation". Note that the total evacuation time was calculated as the time that all occupants move from their initial locations to the end of escalators or stairs in concourse. 


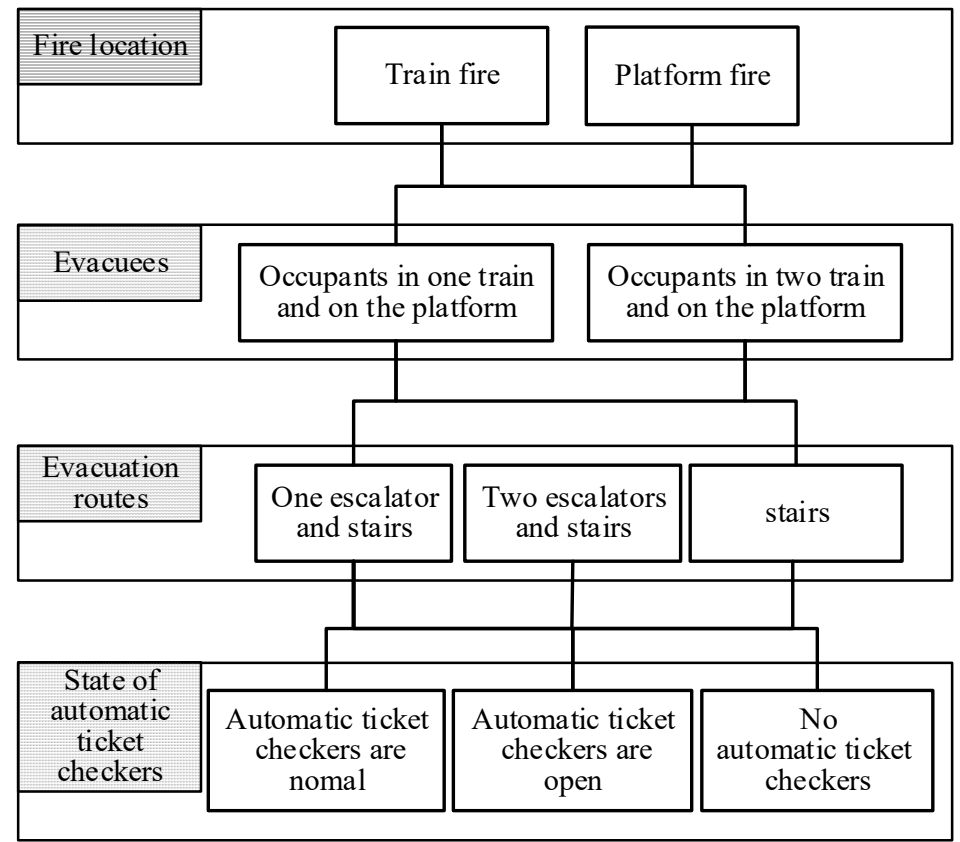

Figure 3. Different cases of fire and corresponding evacuation situations.

Table 1. Summary of evacuation settings in this study.

\begin{tabular}{|c|c|c|c|c|c|}
\hline Strategy & Fire Case & $\begin{array}{c}\text { Occupants } \\
\text { (Person) }\end{array}$ & $\begin{array}{l}\text { Service Condition } \\
\text { of Escalators }\end{array}$ & $\begin{array}{c}\text { Service Condition of } \\
\text { Automatic Ticket } \\
\text { Checkers }\end{array}$ & Evaluation Goal \\
\hline \multirow{3}{*}{$\mathrm{S} 1$} & Case 1 & 378 & None escalator is & & \multirow{9}{*}{$\begin{array}{l}\text { Test the effects of service } \\
\text { condition of escalators on } \\
\text { evacuation efficiency } \\
\text { under different fire } \\
\text { conditions. }\end{array}$} \\
\hline & Case 2 & 1474 & used as fixed & - & \\
\hline & Case 3 & 2570 & evacuation passage & & \\
\hline \multirow{3}{*}{$\mathrm{S} 2$} & Case 1 & 378 & One escalator is used & \multirow{3}{*}{-} & \\
\hline & Case 2 & 1474 & as fixed evacuation & & \\
\hline & Case 3 & 2570 & passage & & \\
\hline \multirow{3}{*}{ S3 } & Case 1 & 378 & Two escalators are & \multirow{3}{*}{-} & \\
\hline & Case 2 & 1474 & used as fixed & & \\
\hline & Case 3 & 2570 & evacuation passages & & \\
\hline \multirow{3}{*}{$\mathrm{S} 4$} & Case 1 & 378 & & \multirow{3}{*}{ Normal } & \multirow{9}{*}{$\begin{array}{l}\text { Test the effects of service } \\
\text { condition of automatic } \\
\text { ticket checkers on } \\
\text { evacuation efficiency } \\
\text { under different fire } \\
\text { conditions. }\end{array}$} \\
\hline & Case 2 & 1474 & & & \\
\hline & Case 3 & 2570 & & & \\
\hline \multirow{3}{*}{ S5 } & Case 1 & 378 & Two escalators are & \multirow{3}{*}{ Open } & \\
\hline & Case 2 & 1474 & used as mxed & & \\
\hline & Case 3 & 2570 & & & \\
\hline \multirow{3}{*}{ S6 } & Case 1 & 378 & & & \\
\hline & Case 2 & 1474 & & \multirow[t]{2}{*}{ None } & \\
\hline & Case 3 & 2570 & & & \\
\hline
\end{tabular}

Strategy 4-6 were considered for examining the effects of different usage of automatic ticket checkers on evacuation efficiency under three fire cases. In S4, the service condition of automatic ticket checkers was set to be normal. In S5, all automatic ticket checkers were fully open and occupants could directly pass through. In S6, all automatic ticket checkers were removed. Not that for S4 to S6, two escalators were used as fixed evacuation passages.

\subsection{Results and Discussion}

\subsubsection{Effects of Escalators on Evacuation}

Escalators and stairs were identified as the bottleneck of metro stations [23,24]. According to the Chinese metro design standards, all evacuees must evacuate to a safe place from the metro platform in 
six minutes (including one minute of response time) [25]. This rule is the so called "five-minute rule". The evacuation performance of escalators and stairs were simulated and evaluated. As mentioned above, case 1, case 2, and case 3 correspond to three basic cases of fire, respectively. When a fire occurs on the platform or in a train, all occupants on the platform should be evacuated through stairs. The elevators will turn off or be used as fixed evacuation passage. Nine scenarios were simulated to investigate the effects of different service conditions of escalators on evacuation time, and the simulation results are shown in Table 2. The total evacuation time (exclude one minute of response time) refers to the time that all the occupants evacuate from their initial location to the end of escalators or stairs in concourse.

Table 2. Total evacuation time for Strategy 1 to Strategy 3 (S1 to S3).

\begin{tabular}{cccccc}
\hline Fire Case & Strategy & $\begin{array}{c}\text { Occupants } \\
\text { (Person) }\end{array}$ & $\begin{array}{c}\text { Total Evacuation } \\
\text { Time (s) }\end{array}$ & $\begin{array}{c}\text { Relative } \\
\text { Effectiveness (\%) }\end{array}$ & OPS \\
\hline \multirow{3}{*}{ Case 1} & S1 & 378 & 123 & - & 0.381 \\
& S2 & 378 & 125 & -1.6 & 0.396 \\
& S3 & 378 & 88 & 28.5 & 0.130 \\
\hline \multirow{3}{*}{ Case 2 } & S1 & 1474 & 425 & - & 0.420 \\
& S2 & 1474 & 428 & -0.71 & 0.525 \\
& S3 & 1474 & 295 & 30.6 & 0.260 \\
\hline \multirow{3}{*}{ Case 3 } & S1 & 2570 & 735 & - & 0.454 \\
& S2 & 2570 & 756 & -2.9 & 0.558 \\
& S3 & 2570 & 488 & 33.6 & 0.267 \\
\hline
\end{tabular}

As shown in Table 2, the total evacuation time of case 1 satisfied the "five-minute rule", indicating all evacuation strategies fulfill the demand of safe evacuation when a platform fire happens. For fire case 2, the total evacuation time of S3 met the requirement of "five-minute rule" while the other two evacuation scenarios did not. This indicates that when a train fire happens and only one train is in the station (i.e., case 2), the use of two fixed escalators is more effective and essential for safe evacuation. Regarding case 3, no evacuation strategies ensured a safe evacuation. Nevertheless, the use of both the stopped escalators (i.e., strategy 3 ) significantly reduced the total evacuation time (reduce by $33.6 \%$ ), compared to the other two strategies.

What is more, the use of both stopped escalators is more effective when train fire happens, compared to platform fire cases $(30.6 \%$ or $33.6 \%$ vs. $28.5 \%$ in Table 2$)$. Thus, it is necessary to use escalators as fixed evacuating passage when a train fire happens. Taking strategy 1 as the baseline strategy, the other two strategies (i.e., S2 and S3) are compared to S1 for relative evacuation effectiveness. It was observed that the total evacuation time of S3 is much lower than that of S1, which indicates that the use of both stopped escalators has an enhanced effect on reducing the total evacuation time (by 28.5\%). This is similar for case 2 and case 3, that the use of both escalators improved the evacuation efficiency by $30.6 \%$ and $33.6 \%$, respectively. As for S2 (i.e., using only one stopped escalator as fixed evacuating passage), the total evacuation time is a bit higher than $\mathrm{S} 1$ for case 2 and case 3 . This implies that using one stopped escalator did not increase but decreased the evacuation efficiency, compared to no usage of escalators. This phenomenon can be further explained by analyzing the optimal productivity statistics (OPS):

$$
O P S=\frac{\sum_{i=1}^{n}\left(T E T-E E T_{i}\right)}{(n-1) T E T},
$$

where $n$ is the number of used exits, $E E T_{i}$ is the time of the last occupant evacuates from exit $i$, and TET is the total evacuation time and TET is equal to the maximum value of $E E T_{i}$.

The OPS represents the balance degree of service time of all the employed exits (i.e., stair and/or escalator in this study). The range of OPS is from 0 to 1 and the lower OPS is, the more balanced service time the used exits achieve. If OPS is 0 , it indicates a very balanced use of all exits which have an equal service time. While if OPS is 1.0, it represents a very unbalanced use of exits that at least one is unused. 
As shown in Table 2, the OPS of S2 is a bit higher than that of S1 (i.e., 0.395 vs. 0.381) for fire case 1. This shows a more unbalanced use of exits for S2, which resulted in longer evacuation time. Similar results can be found for fire case $2(0.525$ vs. 0.420$)$ and case $3(0.558$ vs. 0.454$)$. It can be observed from the simulation process that occupants tend to evacuate through the nearest stairs and/or escalators. As such, the combined use of stair and escalator had a higher evacuation efficiency compared to only using stairs for evacuation. For S2, at the late stage of evacuation, the part of the area with only stairs in use could be much more crowded than the other area where both escalators and stairs can be used. This unbalanced usage condition could create a bottleneck and thus decrease the overall evacuation efficiency. What is more, a strong positive correlation was identified between evacuation time and OPS (see Table 2). Thus, the evacuation efficiency can be improved by passenger organization as well as safe trainings to achieve a more balanced use of all evacuation passages (i.e., stairs and/or escalators).

Figure 4 shows the comparison of different evacuation strategies. When two escalators were both used for fixed evacuation passages, the highest evacuation efficiency was achieved for all three fire cases. Interestingly, the evacuation efficiency of S2 was initially higher than that of S1 at the early stage, for all three fire cases. However, at the late stage, the evacuation efficiency of S2 became lower than that of S1. As mentioned above, the use of exits became largely unbalanced at the late stage of evacuation under three fire cases, resulting in a relatively low evacuation efficiency.

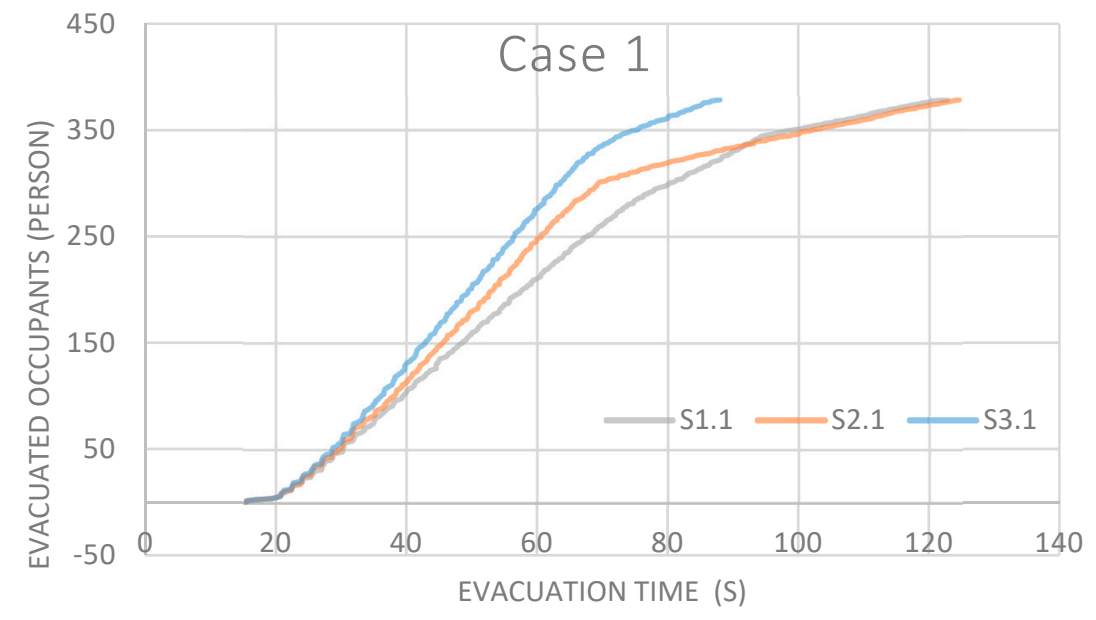

(a) Evacuation Time of S1, S2, and S3 for Fire Case 1.

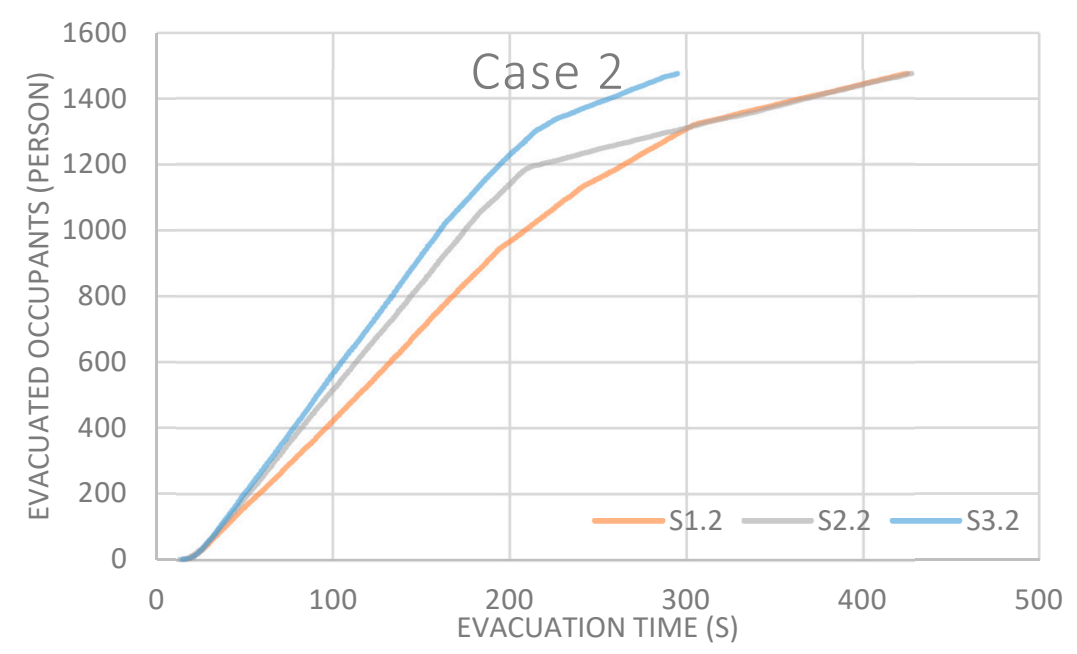

(b) Evacuation Time of S1, S2, and S3 for Fire Case 2.

Figure 4. Cont. 


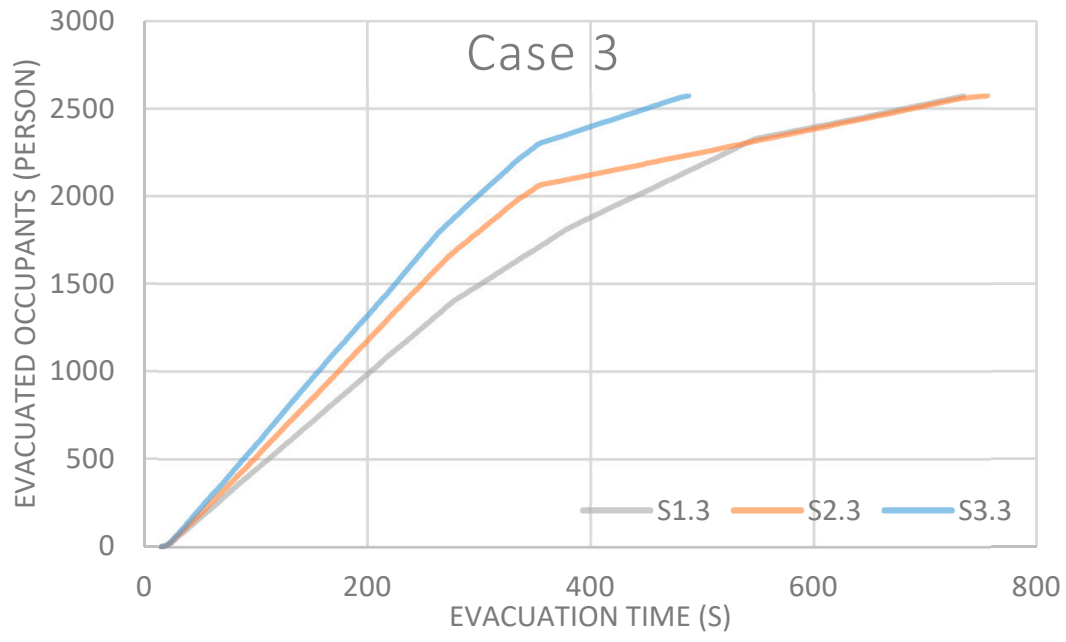

(c) Evacuation Time of S1, S2, and S3 for Fire Case 3.

Figure 4. Effects of escalators on performance of platform evacuation in different cases of fire.

\subsubsection{Effects of Automatic Ticket Checkers on Evacuation}

Automatic ticket checkers enable metro stations to deal with passenger flow efficiently under normal circumstance. However, they could also be bottlenecks under emergency conditions. Thus, the effect of automatic ticket checkers on metro evacuation should be carefully evaluated.

The total evacuation time in this section was calculated as the time all occupants were evacuated from their initial positions to the automatic ticket checkers. Nine experiments were simulated to investigate the effects of automatic ticket checkers on evacuation (see Table 3). Based on the simulation results, S4 had the longest evacuation time than S5 and S6 for all fire cases. This indicates that when a fire happens in a train or on the platform, automatic ticket checkers will decrease evacuation efficiency if they are still in normal status. The evacuation efficiency was largely improved (about $28 \%$ to $38 \%$ ) when the automatic ticket checkers are fully open (i.e., S5). Strategy 6 did not result in an obvious improvement over strategy 5 ( $28.8 \%$ vs. $30.7 \%, 36.0 \%$ vs. $39.4 \%$, and $38.5 \%$ vs. $39.9 \%$ in Table 3 ). This finding was consistent with previous literature [8].

Table 3. Total evacuation time in S4 to S6 (S4 to S6).

\begin{tabular}{ccccc}
\hline Fire Case & Strategy & $\begin{array}{c}\text { Occupants } \\
\text { (Person) }\end{array}$ & $\begin{array}{c}\text { Total Evacuation } \\
\text { Time (s) }\end{array}$ & $\begin{array}{c}\text { Relative } \\
\text { Effectiveness (\%) }\end{array}$ \\
\hline \multirow{4}{*}{ Case 1} & S4 & 378 & 153 & - \\
& S5 & 378 & 109 & 28.8 \\
& S6 & 378 & 106 & 30.7 \\
\hline \multirow{3}{*}{ Case 2 } & S4 & 1474 & 480 & - \\
& S5 & 1474 & 307 & 36.0 \\
& S6 & 1474 & 291 & 39.4 \\
\hline \multirow{2}{*}{ Case 3 } & S4 & 2570 & 825 & - \\
& S5 & 2570 & 507 & 38.5 \\
& S6 & 2570 & 496 & 39.9 \\
\hline
\end{tabular}

According to Figure 5, the evacuation efficiency of S6 is slightly better than S5 at the beginning. However, the efficiency of the two strategies are almost the same at the end of evacuation process. During simulations, the occupant density initially increased and then decreased around automatic ticket checkers. Thus, the effect of automatic ticket checkers as bottlenecks should also be large at the beginning when the occupant density is increasing. However, such bottleneck effect was not that large for the whole evacuation process. 


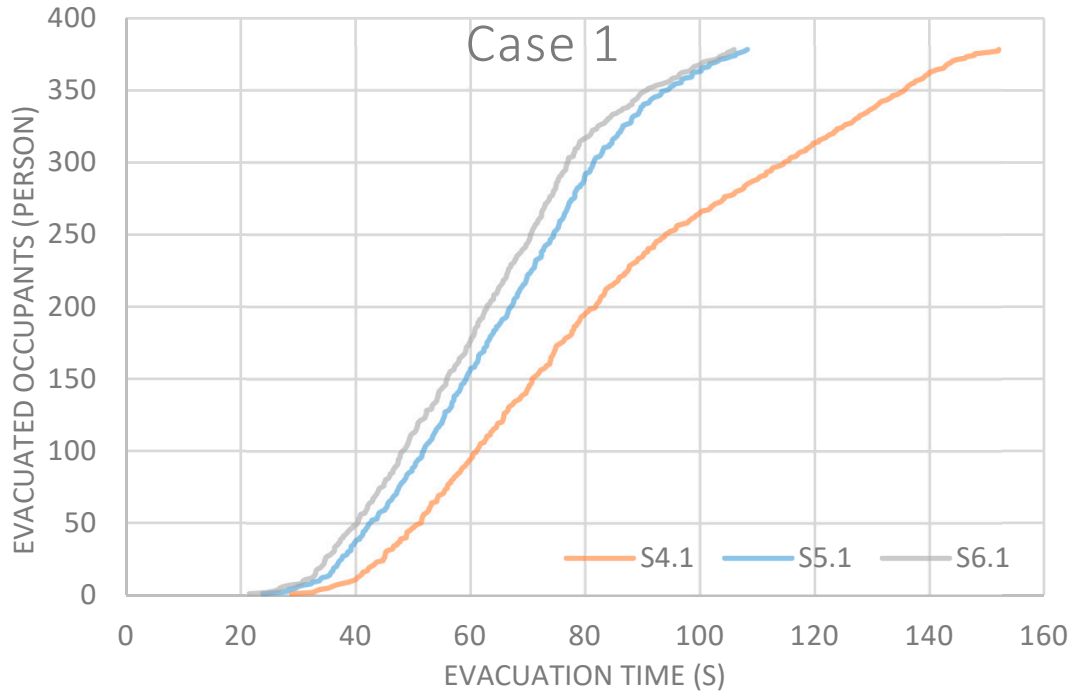

(a) Evacuation Time of S4, S5, and S6 for Fire Case 1.

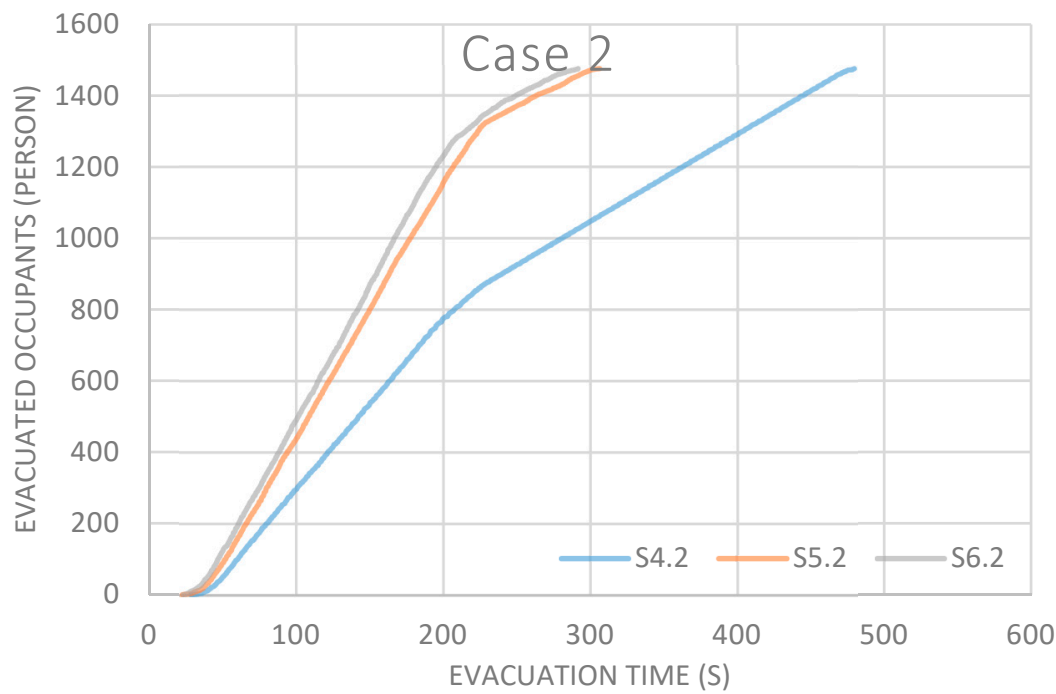

(b) Evacuation Time of S4, S5, and S6 for Fire Case 2.

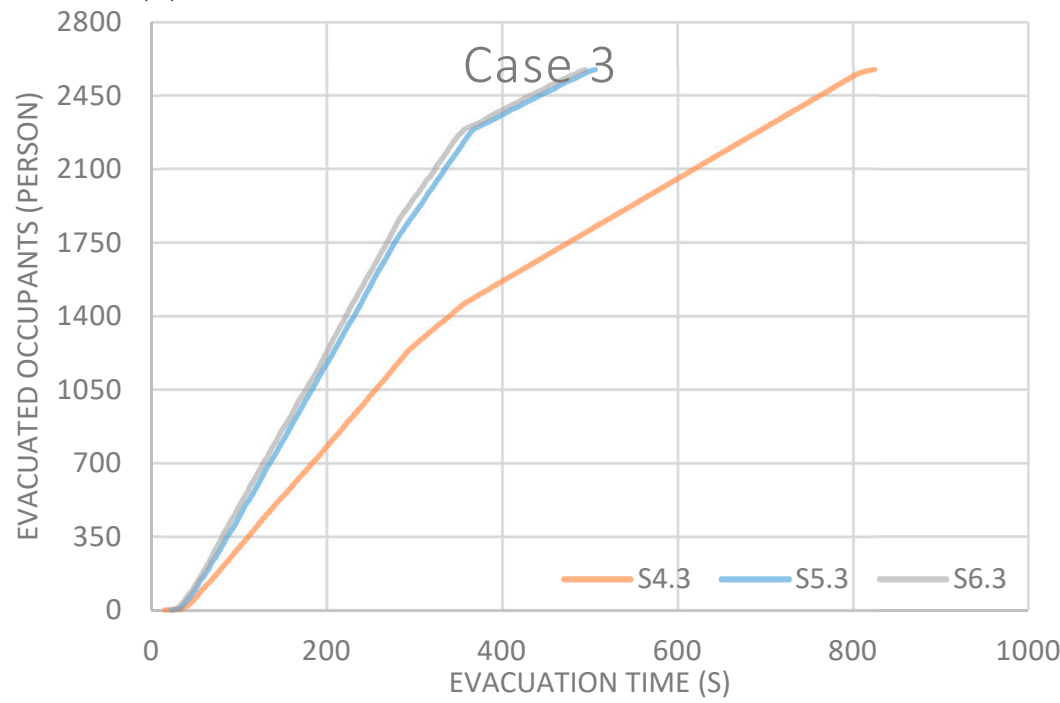

(c) Evacuation Time of S4, S5, and S6 for Fire Case 3.

Figure 5. Evacuation performances for Strategy 4 to Strategy 6. 


\section{Conclusions}

Metro stations are public transportation infrastructure, where a large number of people could gather around. The passenger traffic volume has reached or exceeded the designed transport capacity in many big cities in China. Serious incidents happening in metro stations would cause serious casualties and property losses. Thus, the safety evacuation in metros stations has drawn great public attention. Given that China has entered the stage of rapid construction of metro network, the evacuation capacity of a metro station should be carefully evaluated.

In this study, a metro station in Shanghai, China was selected for simulation modeling. First, a simulation model was developed based on the actual layout of the station. Then, passenger flow data were collected, based on which important simulation parameters such as passenger demand and occupant parameters were calibrated. After that, three fire cases and multiple evacuation strategies with different usage of escalators and automatic ticket checkers were considered and simulated based on the simulation model.

According to the research results, the normal capacity of the metro station can satisfy a safe evacuation when a platform fire happens. However, additional capacity should be required to ensure a safe evacuation when a train fire happens. Under this circumstance, the use of two stopped escalators as fixed evacuation passages could be considered as effective and essential for safe evacuation. However, an unbalanced usage of escalators as evacuation passages could even decrease evacuation efficiency, compared to using stairs only. The evacuation efficiency can be further improved by fully opening automatic ticket checkers instead of maintaining them at normal status. Removing automatic ticket checkers does not have additional effects on improving evacuation efficiency. In general, this study provides valuable information for facility design and emergency evacuation in metro stations in China.

Author Contributions: Conceptualization, C.W.; methodology, C.W., and Y.S.; software, Y.S.; validation, C.W., and Y.S.; resources, C.W.; data curation, C.W., and Y.S.; writing-original draft preparation, C.W., and Y.S.; writing-review and editing, C.W., and Y.S. All authors have read and agreed to the published version of the manuscript.

Funding: This research was funded by Shanghai Pujiang Program (15PJC093).

Acknowledgments: The authors appreciate research efforts from Qingyuan Ma, Hao Liu.

Conflicts of Interest: The authors declare no conflict of interest.

\section{References}

1. Prediction of New Mileage and Total Mileage of China's Metro. Available online: https://www.sohu.com/a/ 100092394_119556 (accessed on 25 December 2019).

2. Shi, C.; Zhong, M.; Nong, X.; He, L.; Shi, J.; Feng, G. Modeling and safety strategy of passenger evacuation in a metro station in China. Saf. Sci. 2012, 50, 1319-1332. [CrossRef]

3. Fennel, D. Investigation into the King's Cross Underground Fire; Her Majesty's Stationery Office: London, UK, 1988.

4. Hong, W.H. The progress and controlling situation of Daegu Subway fire disaster. In Proceedings of the 6th Asia-Oceania Symposium on Fire Science and Technology, Daegu, Korea, 17-20 March 2004.

5. Jiang, C.S.; Yuan, F.; Chow, W.K. Effect of varying two key parameters in simulating evacuation for subway stations in China. Saf. Sci. 2010, 48, 445-451. [CrossRef]

6. Lei, W.; Li, A.; Gao, R.; Hao, X.; Deng, B. Simulation of pedestrian crowds' evacuation in a huge transit terminal subway station. Phys. A Stat. Mech. Its Appl. 2012, 391, 5355-5365. [CrossRef]

7. He, L.; Zhong, M.H.; Shi, C.L.; Shi, J.H.; Chen, H.; Xu, Q.X. Experimental research on investigation of metro passenger evacuation behaviors in case of emergency. In Proceedings of the Fifth International Conference on Pedestrian and Evacuation Dynamics (PED 2010), Gaithersburg, MD, USA, 8-10 March 2010.

8. Zia, K.; Ferscha, A.; Riener, A.; Wirz, M.; Roggen, D.; Kloch, K.; Lukowicz, P. Scenario based modeling for very large scale simulations. In Proceedings of the 2010 IEEE/ACM 14th International Symposium on Distributed Simulation and Real Time Applications, Fairfax, VA, USA, 17-20 October 2010. 
9. Ferscha, A.; Zia, K. Lifebelt: Crowd evacuation based on vibro-tactile guidance. IEEE Pervasive Comput. 2010, 9,33-42. [CrossRef]

10. Wang, C.; Xu, C.; Dai, Y. A Crash Prediction Method Based on Bivariate Extreme Value Theory and Video-Based Vehicle Trajectory Data. Accid. Anal. Prev. 2019, 123, 365-373. [CrossRef] [PubMed]

11. Wang, C.; Xu, C.; Xia, J.; Qian, Z. Modeling Faults among E-Bike-Related Fatal Crashes in China. Traffic Inj. Prev. 2017, 18, 175-181. [CrossRef] [PubMed]

12. Kuligowski, E.D.; Peacock, R.D. Review of Building Evacuation Models; Technical Note 1471; Department of Commerce, National Institute of Standards and Technology: Gaithersburg, MD, USA, 2005; Volume 6, 153p.

13. Wang, T.; Jiang, C.S.; Ling, Y. Assessment Report on the Current Safety Status of Beijing Subway System; Beijing Municipal Institute of Labor Protection: Beijing, China, 2004.

14. Ronchi, N. Modeling Total Evacuation Strategies for High-Rise Buildings. In Building Simulation; Springer: Berlin/Heidelberg, Germany, 2014.

15. MacDonald, M. Simulation of Transient Evacuation and Pedestrian Movement-STEPS User Manual; Mott MacDonald Simulation Group: Croydon, UK, 2010.

16. Zhang, Y.S.; Yao, E.; Zhang, Y.; Zheng, K. Estimating metro passengers' path choices by combining self-reported revealed preference and smart card data. Transp. Res. Part C 2018, 92, 76-89. [CrossRef]

17. Wu, G.Y.; Chien, S.; Huang, Y. Modeling the occupant evacuation of the mass rapid transit station using the control volume model. Build. Environ. 2010, 45, 2280-2288. [CrossRef]

18. Yang, P.; Li, C.; Chen, D. Fire emergency evacuation simulation based on integrated fire-evacuation model with discrete design method. Adv. Eng. Softw. 2013, 65, 101-111. [CrossRef]

19. Enrico, R.; Nilsson, D. Fire evacuation in high-rise buildings: A review of human behavior and modeling research. Fire Sci. Rev. 2013, 2, 7.

20. Shanghai Metro. Available online: https://en.wikipedia.org/wiki/Shanghai_Metro (accessed on 16 January 2020).

21. Jeon, G.Y.; Kim, J.Y.; Hong, W.H.; Augenbroe, G. Evacuation performance of individuals in different visibility conditions. Build. Environ. 2011, 46, 1094-1103. [CrossRef]

22. Kobes, M.; Helsloot, I.; Vries, B.; Post, J.G.; Oberije, N. Way finding during fire evacuation: An analysis of unannounced fire drills in a hotel at night. Build. Environ. 2010, 45, 537-548. [CrossRef]

23. Xie, Z.L.; Zhang, J.W.; Wei, L.; Liu, J. Safe evacuation from subway platform under fire. China Saf. Sci. J. 2004, 14, 21-25.

24. Kinsey, M.J.; Galea, E.R.; Lawrence, P.J. Stairs or lifts? A study of human factors associated with lift/elevator usage during evacuations using an online survey. In Proceedings of the Fifth International Conference on Pedestrian and Evacuation Dynamics (PED 2010), Gaithersburg, MD, USA, 8-10 March 2010.

25. Beijing Municipal Commission of Urban Planning. Code for Design of Metro, GB 50157-2003, China National Stand. 2003. Available online: http://www.jianbiaoku.com/webarbs/book/1027/1073253.shtml (accessed on 16 January 2020).

(C) 2020 by the authors. Licensee MDPI, Basel, Switzerland. This article is an open access article distributed under the terms and conditions of the Creative Commons Attribution (CC BY) license (http://creativecommons.org/licenses/by/4.0/). 